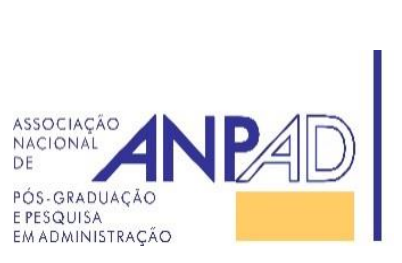

Available online at http://www.anpad.org.br/bar

BAR, Rio de Janeiro, v. 14, n. 2, art. 3, e170006, 2017

\title{
Sociomaterial Practices: Challenges in Developing a Virtual Business Community Platform in Agriculture
}

Norberto Hoppen ${ }^{1}$ Amarolinda da Costa Zanela Klein ${ }^{1}$ Eduardo Henrique Rigoni ${ }^{1}$

Universidade do Vale do Rio dos Sinos ${ }^{1}$

Received 20 January 2017; received in revised form in 22 June 2017 (this paper has been with the authors for two revisions); accepted in 22 June 2017; first published online 14 July 2017. Editor's note. Carlo Gabriel Porto Bellini served as Action Editor for this article. 


\begin{abstract}
Virtual business communities (VBC) are virtual networks of people who share common interests and comprise online software platforms that enables the fast exchange of information, collaboration and business interactions. From 2011 to 2015, we developed a design science research to create a VBC platform for an agricultural cluster of flower growers in the South of Brazil. The goal of this platform was to help to structure and strengthen this cluster by bringing together buyers and sellers while fostering cooperation to boost cluster competitiveness and economic development in the region. However, a number of challenges surfaced during the process, which led to a failure in the VBC platform's diffusion. We adopted a sociomaterial perspective based on the mangle of practice concept (Pickering, 1993) to investigate this failure, by analyzing the key challenges involved in developing a VBC platform in an agricultural context. As its main result, this paper reveals the mangling process during the design and application of the VBC platform and details the different instances of tuning between the participants and the technology. We observed resistance and factors that weakened cooperation and resulted in a lack of governance rules, which are key to the success of a VBC platform.
\end{abstract}

Key words: virtual business communities; mangle of practice; ICT adoption; agriculture; design science research. 


\section{Introduction}

Virtual business communities (VBC) are defined in this paper as virtual networks of people who share common interests and comprise online software platforms that enable the fast exchange of information, collaboration and business interactions. They are mediated social spaces that allow groups to achieve business goals and have a functional nature (Bagozzi \& Dholakin, 2002). In the concept of VBC proposed in this paper, economic agents work together to create value-added processes with the support of Information and communication technology (ICT) platforms (Hackney, Burn, \& Salazar, 2004; Markus \& Loebbecke, 2013). Studies involving market organizations have focused on the economic impacts of such online environments, including lower transaction costs for buyers and sellers, 24/7 operations, better pricing, wider availability of product information, improved transparency of the price formation process, less collusion among buyers, less exploitation by middlemen and more streamlined supply chains (Banker, Mitra, \& Sambamurthy, 2011; Kambil \& Van Heck, 1998).

A key economic sector for the application of VBC platforms is agriculture, particularly in developing countries. A VBC platform can provide informational services, transactional services and egovernance to agricultural value chains (Food and Agriculture Organization of the United Nations [FAO], 2013; The World Bank, 2011), and in this way they (a) deliver access to price information, (b) manage production systems and (c) foster financial inclusion. The literature provides some examples of these applications, such as e-Choupal and iKisan.com in India, FarmerNet in Sri Lanka and DrumNet and KACE in Kenya (Ali \& Kumar, 2011; FAO, 2013; Rao, 2007). Many developing countries are affected by problems of limited access to knowledge and large-scale information asymmetries in almost all stages of the agricultural value chain, which results in local communities being exploited and generates inefficiencies across the chain (Ali \& Kumar, 2011; Rao, 2007). ICT can help to create opportunities for dialogue between previously isolated actors in agricultural supply chains and facilitate collaborative alliances between farmers and consumers. Information and knowledge are important factors in accelerating agricultural development by means of appropriate production planning, the adoption of improved cultivation practices and effective post-harvest management and marketing (Ali \& Kumar, 2011; Vallauri, 2014). Access to markets requires logistics and low transaction costs, which must be combined with up-to-date market information (Magesa, Michael, \& Ko, 2015).

Considering the potential of VBC platforms in the development of agriculture in developing countries, we present the results of a four-year longitudinal study based on design science research (Lacerda, Dresch, Proença, \& Antunes, 2013; Peffers, Tuunanen, Rothenberger, \& Chatterjee, 2007) where a VBC platform in the flower sector was created. This sector has approximately 8,200 flower growers in Brazil and their gross revenue amounted to \$ 2.42 billion in 2014 (Instituto Brasileiro de Floricultura [IBRAFLOR], 2015).

The VBC platform was developed collaboratively with members of a local flower association (henceforth Flowers Associated) that represents the cluster studied. The association showed interest in our project to create a technological artifact (i.e., software) that could support the economic development of the cluster. Flowers Associated presented characteristics of a face-to-face community. It is a group in which individuals come together around a shared purpose, interest and goal (Rothaermel \& Sugiyama, 2001); and there were leaders that could be involved in the project (Koh, Kim, Butler, \& Bock, 2007). The goal was to bring together buyers and sellers to foster collaboration and create business alliances among cluster firms, in order to achieve better collective efficiency by means of joint sales and the sharing of costs and logistics services.

This issue is relevant because, for example, Banker, Mitra and Sambamurthy (2011) highlighted the importance of carrying out empirical research on the impact of ICT on agricultural supply chains in developing countries, because ICT can positively affect the lives of millions of farmers around the world. This impact, however, has been poorly investigated in the information systems literature, which tends to emphasize demographic and individual variables that may influence the diffusion of ICT in agriculture (see, for instance, Ali \& Kumar, 2011; Botsiou \& Dagdilelis, 2013; Das, 2014; Läpple, 
Renwick, \& Thorne, 2015). Some studies investigate factors such as access to technology, connectivity and digital inclusion among farmers (Moghaddam \& Khatoon-Abadi, 2013; Rao, 2007) and focus primarily on technology and the benefits derived from the use of ICT by clusters, market organizations and virtual communities. However, these studies tend to overlook the development process of VBC platforms and the challenges faced when trying to make these benefits possible: there are few references to social elements such as the huge gaps in farmers' knowledge, their access to and use of IT, the diversity of organizational structures and processes to come across when attempting to implement ICT to support agriculture.

Therefore, our research question is: What are relevant challenges in the development and diffusion of VBCs platforms in agriculture? Our goal with this article is to analyze the main challenges faced when trying to develop and spread the use of a VBC platform in an agricultural cluster, while considering a sociomaterial perspective based on Pickering's mangle of practice concept (1993).

The mangle of practice is a relational perspective that can be broadly characterized as sociomaterial (Stein, Newell, Wagner, \& Galliers, 2014). A sociomaterial perspective integrates technology, people and their work, and organizations when attempting to understand the constitutive entanglement of the social and the material in organizational life (Jones, 2014). We analyzed the process involved in designing the software and the reasons for the failure in implementing it, because the proposed VBC software platform was not adopted by the community (Flower Association) that contributed to its development.

The research deals with a particularly complex problem (Hevner, March, Park, \& Ram, 2004) that is characterized by (a) varying requirements and constraints in an ill-defined context, (b) complex interactions between elements of the problem and its solution, (c) flexibility to change the design processes and artifacts, and (d) critical dependence on human cognitive and social abilities to produce effective solutions.

Lessons learned from our research can contribute to future developments of VBC platforms for agricultural clusters, networks, informal business communities or collaborative groups, particularly in relation to the development of ICT in agricultural value chains in developing countries. The discussion of our experience can also prove useful for policymakers and researchers interested in longitudinal design science research.

In the following section, we review the literature on VBC. We then present and discuss our theoretical foundation: Pickering's mangle of practice (1993). An outline of the research method, followed by a description of the process used to develop the VBC platform, a discussion and concluding remarks make up the remainder of the article.

\section{Virtual Business Communities}

Virtual business communities (VBC) are defined in this paper as virtual networks of people who share common interests and comprise online software platforms that enable the fast exchange of information, collaboration and business interactions. They are mediated social spaces that allow groups to achieve business goals. Such platforms connect buyers, sellers, suppliers, financial agents and R\&D institutions that can work in tandem to create value-added processes with the support of ICT (Hackney et al., 2004; Markus \& Loebbecke, 2013). As in other types of virtual communities, members participate by volitional choice, attempting to achieve mutual goals, and the environment is digitally mediated, allowing groups to be formed and sustained through virtual communication processes (Bagozzi \& Dholakin, 2002). There are some drivers that encourage members' participation, such as the involvement of leaders, high levels of offline interactions and the usefulness of the community (Koh et al., 2007). VBC members may be individuals or representatives of participating organizations. These organizations present different characteristics and their number can range from just a few to several. 
VBC require the redesign of participants' core business processes, the development of new organizational forms and interorganizational structures, and a strategic change that ranges from competition to collaboration (Hackney et al., 2004). These aspects include governance, namely, norms, rules, information monitoring, incentives and sanctions. Interactions between VBC participants are based on virtual platforms with digitized and standardized business processes that should be used by all members (Banker et al., 2011; Porter, 2004). Whatever the degree of heterogeneity among members, these processes must be the same.

Ostrom (1990) stated that in situations of interdependence between heterogeneous actors, collective actions are taken with the use of institutions, which are defined as a set of rules and standards effectively applied by a group of individuals to organize their activities. Norms correspond to the internal values of the group, while rules are representations shared with the outside. The emergence of collective actions stimulates collaboration in achieving collective results. These actions depend on individual incentives to participate in decision-making groups and require several collective tasks, ranging from the coordination of actions to the sharing of information, from developing common rules to putting in place conflict resolution mechanisms. Violation of these aspects leads to progressive sanctions.

The use of digital platforms increases the amount of combinations of business processes (e.g., information search, valuation, logistics), thus creating business opportunities that were previously out of reach for individual firms (Banker et al., 2011; Kambil \& Van Heck, 1998), and it also increases the likelihood of different business partners identifying shared interests.

The development process of a VBC platform concerns a continuous interaction between human actors and technology. To analyze this process we adopted a sociomaterial theoretical approach, which is presented in the next section.

\section{The Mangle of Practice}

As previously explained, a sociomaterial approach is focused on understanding the constitutive entanglement of the social and the material in organizational life (Jones, 2014). Pickering's mangle of practice concept (1993) was considered in order to understand the mutual interdependence between social and technical elements when developing a VBC platform. It concerns the interplay between material and human agencies, seen as a continuous dialectical process that evolves over time through resistance and accommodation, thus shaping trajectories of change (Pickering, 1995). The process of mangling evokes the unpredictable, emergent quality of the interaction between human and material agencies in an asymmetric relationship.

In relation to ICT, the interaction process between human and material agents can be quite complex. This process results from the intangibility of products - platforms with services and informational content - and their use by different people in a diverse range of organizational and interorganizational work practices. In this context, the mangle of practice approach may help to explain why the achievement of intentions in information systems design and their implementation is potentially problematic. Unintended consequences and unforeseen contingencies of social actions can emerge and the use of a system can escape the ordering intentions of its designers through a particular appropriation process (Jones, 1999). Figure 1 shows the main elements that constitute the mangle of practice process: 


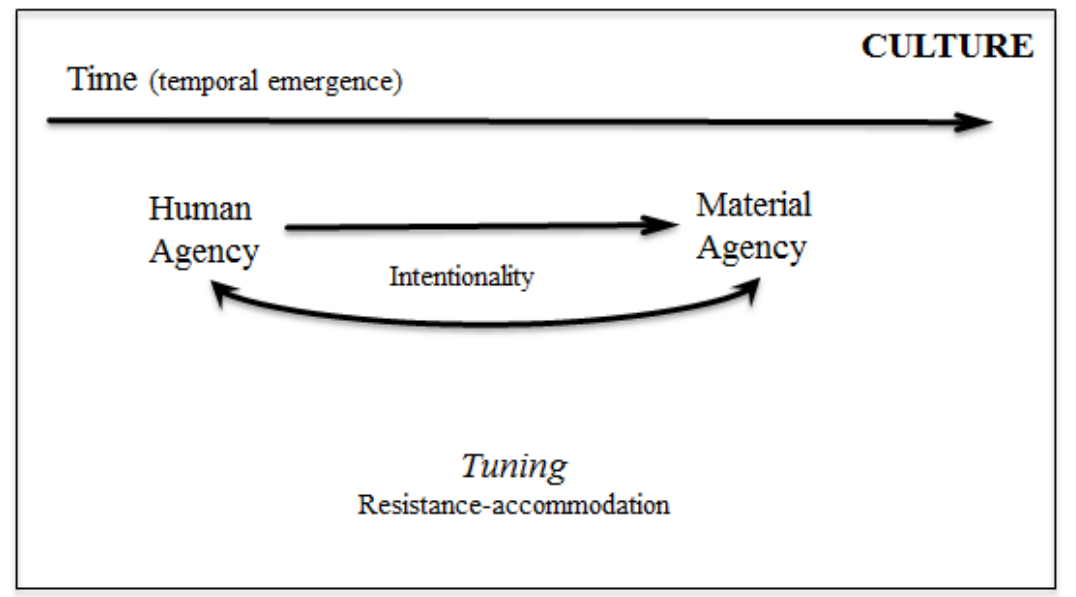

Figure 1. The Mangle of Practice Process

Source: Prepared by the authors from Pickering, A. (1993). The mangle of practice: Agency and emergence in the sociology of science. The American Journal of Sociology, 99(3), 559-589. https://doi.org/10.1086/230316

- Human agency: Human agency concerns goals, plans and purposes intended by humans (Giddens, 1984; Jones, 1999). In our research, participants of the development process of the VBC platform are the economic agents, researchers and software developers.

- Material agency: Material agency is defined as the capacity of nonhuman entities to act on their own (Leonardi, 2011). It refers to what technology can do. In our case, it applies to what the VBC platform can do on behalf of the assemblage of services and information to be accessed by users.

- Intentionality: Humans intend to pursue results through strategies, purposes, plans and goals; material agency lacks this intentionality (Jones, 1999).

- Temporal emergency: Human agency is, just like material agency, temporally emergent; it emerges in the real time of practice (Pickering, 1993).

- Tuning: Tuning comprises human and material agencies and concerns the dialectical process of resistance and accommodation in relation to one another (Pickering, 1993). It is a process that evolves over time.

- Resistance: Resistance is defined as "a block arising in practice to this or that passage of goaloriented practice" (Pickering, 1995, p. 66). It arises from human or material agents but is always situated within the domain of human purpose. Resistance is emergent over time (Pickering, 1995).

- Accommodation: Accommodation comprises the actions employed by humans to overcome or avoid resistance. The interplay of human and material agencies stabilizes one another. Thus, when humans encounter resistance and wish to achieve an intended goal, they revise purposes, intentions or practices or adjust technical parameters (Martini, Massa, \& Testa, 2013).

Many studies have made use of the mangle of practice concept to analyze empirical cases of ICT creation and diffusion. Venters, Oborn and Barret (2014) developed the concept of digital coordination and proposed a trichordal temporal approach to temporal emergence in order to understand the development and use of digital infrastructure. Martini, Massa and Testa (2013) explored the relationship between human actors and technology in a social media platform developed by an industrial company. They examined how this artifact works and how the platform configured and reconfigured the practices and possibilities of different modes of engagement through internal and external users. Kuk and Davis (2011) adopted the concept of mangling to explain differences between initial and sustained conditions for user participation in the context of service innovation with open data provided by governments. Svahn, Henfridsson and Yoo (2009) developed a sociomaterial perspective to appreciate tensions between different technological regimes in digital innovation: the logic of innovation practices based on 
components (products) and the logic based on services. Lastly, Steinkuehler (2006) applied the concept of mangling to analyze the development process of an online multiplayer game.

All these empirical studies considered the dialectical process related to the interaction between humans and ICT over time, adapting Pickering's original theory to different situations.

\section{Research Method}

We performed a four-year longitudinal design science research (Gregor \& Hevner, 2013; Lacerda et al., 2013; Peffers et al., 2007) project. We adopted this research method because it allows knowledge to be built systematically through the development, evaluation and application of an artifact - in our research, the artifact created is the VBC software platform. As Peffers, Tuunanen, Rothenberger and Chatterjee (2007) stated, design science research provides a mental model to analyze, evaluate and present the interplay between social and technical elements in practice.

Our research started at the end of 2011 when first contact was made with the investigated cluster. Data collection started in March 2012 and continued until the end of the project, in January 2015. In this research, we followed the five design stages proposed by Vaishnavi and Kuechler (2004). Figure 2 shows all these research steps in a timeline.

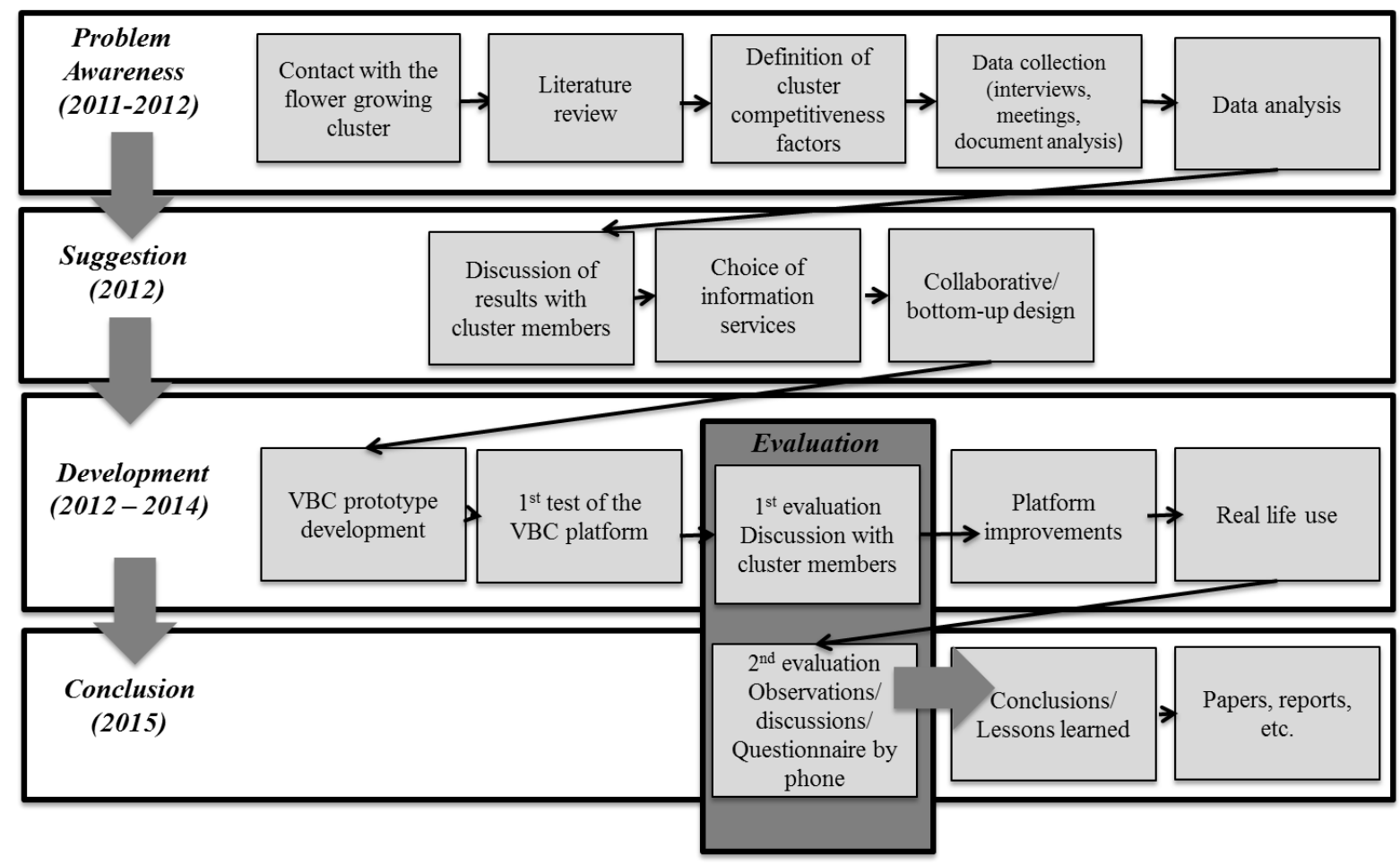

Figure 2. Research Design

1. Problem awareness: This step allowed us to understand the features of the flower cluster and its competitiveness factors. In this stage, theoretical knowledge about organizational clusters and virtual business communities were deepened. The focus was to study the factors that influence the competitiveness of clusters - interorganizational arrangements where the VBC platform aims to make contributions. The factors investigated with the use of a qualitative research instrument were (Hoppen, Rigoni, Klein, \& Ritter, 2016): the cluster's institutional fabric (social community and economic agent cohesion); cluster governance (leadership, leader roles and institutional roles); 
external factors (market, suppliers and regulatory framework); internal factors (human resources [HR], logistics, finances, technology and key work processes); and cluster knowledge interaction. All these factors were explored using a structured interview script applied to 23 different cluster agents: flower growers, suppliers, wholesalers, retailers as well as representatives of governmental agencies and associations. The profile of the interviewees is in Table 1.

Table 1

Interviewees' Details

\begin{tabular}{lcc}
\hline Cluster members interviewed & $\mathbf{N}^{\mathbf{0}}$ of interviews & $\begin{array}{c}\text { Duration } \\
\text { (hour: minute) }\end{array}$ \\
\hline Flower growers & 9 & $16: 29$ \\
\hline $\begin{array}{l}\text { Input suppliers (seeds, breeders, fertilizers, materials for } \\
\text { hothouses, supplements, etc.) }\end{array}$ & 6 & $05: 45$ \\
\hline $\begin{array}{l}\text { Flower wholesalers } \\
\text { Flower retailers }\end{array}$ & 3 & $02: 15$ \\
\hline $\begin{array}{l}\text { Representatives of governmental agencies and associations } \\
\text { related to the flower cluster }\end{array}$ & 3 & $04: 56$ \\
\hline Total & 2 & $06: 52$ \\
\hline
\end{tabular}

Note. Source: Research data.

All the data from documents about the cluster, the 23 interview transcriptions, plus 74 emails exchanged with different members of the cluster, as well as field notes taken during participation in several formal and informal meetings, were registered in a single database in NVivo10®. The meetings with cluster members included an informal barbecue of the cluster association, after work gatherings and formal meetings, such as a summit for cluster members held by the Brazilian Ministry of Agriculture (MAPA). A visit was made to the city of Holambra, in the state of Sao Paulo, which is the best organized flower-growing cluster and the main flower supplier in Brazil. Researchers also attended meetings organized by the Brazilian Flower Farming Institute.

All these data collected were analyzed following the steps indicated by Miles and Huberman (1994): data reduction, data display and conclusion drawing. We used content analysis procedures (Bauer \& Gaskell, 2011) with the support of the software NVivo10®. We categorized and organized the data around cluster competitiveness factors that were identified in the literature and explored them via the qualitative research instrument along with open categories about the cluster's profile and needs. All the data collected in this step guided the next step (suggestions).

2. Suggestions: This step consisted of a first attempt at designing the VBC platform. During a meeting organized by Flowers Associated, approximately 30 cluster members participated in a presentation on the results of the previous research phase (problem awareness), mainly related to the evaluation of the cluster competitiveness factors and existing gaps. These participants discussed their situation and the needs of the cluster and defined the key functionalities of the VBC platform (information services), as detailed in the next section.

3. Development: This step involved the development of a prototype, its validation and trials with users. It also included actions to organize the VBC platform's use, such as the definition of business processes and governance structure. During this process, in addition to a series of informal conversations, approximately 25 cluster members participated in four formal meetings organized by the researchers. In this step, the artifact was introduced in the field to assess the effects of its use in real life conditions. 
4. Evaluation: The artifact was evaluated along the entire design process by means of observations, discussions with members of the cluster, field notes, qualitative analysis of the data collected as well as an analysis of system logs. Therefore, the evaluation process was performed during the steps of suggestions and development, and not only at the end of artifact application. We also carried out a qualitative questionnaire by phone in January 2015 with the users. The objective was to gather final impressions about the VBC platform and the results it generated, as well as the difficulties and barriers faced in its diffusion, complementing the processual evaluation adopted. The instrument was based on the literature on virtual business communities and mobile information systems, adapting the questions and scales already used by the project team to evaluate mobile solutions (Klein, Freitas, $\&$ Barbosa, 2015) in order to focus this research. The questionnaire explored individual perceptions related to the use of the VBC platform, its perceived utility and ease of use, and, particularly, its contribution to the competitiveness of the cluster and individual businesses. This instrument was pretested with a member of the flower cluster (not included in our sample). From a total of 31, 13 cluster members that adopted the VBC platform answered the questionnaire.

5. Conclusion: In order to conclude the project, we performed a final qualitative analysis of the data collected over the study period. The data were organized following the VBC platform development process (see Figure 2). The mangle of practice concept was used as a framework to analyze this process, which considered the interaction between human and technological agencies, as well as the different instances of tuning along the way. We present this analysis in the next section.

\section{The Process of Developing and Diffusing the VBC Platform}

The main challenges faced in each step of the development and diffusion process of the VBC platform are presented in a timeline.

\section{How the process started: a solution seeking a problem}

The idea of the technological artifact (the VBC software platform) was initially conceived as a type of "solution seeking a problem" (Chaudhuri, 2012, p. 1). The process started with a software application that had been developed by computer science researchers involved in the project. In 2009, they created an application for ubiquitous commerce that offered automated search functionalities for business deals between buyers and sellers using location awareness services (Franco, Rosa, Barbosa, Costa, \& Yamin, 2011). This software had not yet been used in a real business environment, so the management researchers of the team foresaw an opportunity for innovation. Given the proximity of the flower-grower cluster to our university and the fact that flowers are highly perishable, the cluster was seen as an obvious choice to test the software. Flowers Associated, the most important association of this cluster, showed interest in developing a platform to support the economic development of its members. Funding for the research project was only secured at the end of 2011, which is when the members of the flower cluster were first approached.

\section{Problem awareness: understanding the business context (around March 2012)}

Contact with the cluster leaders marked the first step of the research process - problem awareness. Our aim was to understand the cluster structure, how it worked, who the main actors were and the problems they faced, especially with regard to cluster competitiveness factors (as already mentioned in the method section). Our goal was not to directly apply the ubiquitous commerce software that had been developed by the computer science researchers of the team to the setting. We wanted instead to understand what sort of problems the flower growers faced, so that we could adapt the software to their specific needs. Therefore, the idea of the artifact evolved to a broader concept, namely the VBC platform. 
During the problem awareness step, we analyzed the cluster and the association based on important characteristics and drivers of cluster competitiveness and virtual communities, with the purpose of understanding the cluster's features, the social community involved, and the level of cohesion and collaboration among cluster members. It was also important to understand how the cluster's leadership operated and what the business rules were. In addition, key elements that affected the competitiveness of the cluster were taken into account. This included market analysis, an understanding of resource distribution and business processes within the cluster as well as the level of knowledge sharing among cluster members.

We adopted an interactive data collection process and used the data to understand the business model of the cluster. This model was used to collect data and interviewees (members of the cluster), leading to the start of discussions on issues concerning the structure of the cluster and the roles of the different economic agents, thereby creating a shared view of their cluster. Even though this was unintentional, a collaborative sense-making process emerged, contributing to the construction of common business understanding about the cluster and the industry itself. Understanding this context (which is described briefly in the next section) was essential to the development of the VBC platform.

\section{The background of the mangle: an agricultural context}

The cluster studied is located in Southern Brazil. It is poorly structured (Berkowitz \& Wolff, 2000) and its 200-odd members include flower growers, suppliers, wholesalers, retailers and representatives of governmental agencies and associations. Most producers work on small family properties. Their production includes cut flowers, garden annuals and perennials, potted plants and other flower products. Production is low-tech (without greenhouses, for example). Their overall level of education is low, but this is changing as a new generation with better education and access to ICT has started to take over. Despite the fact that many producers and even workers in this setting make use of computers and smartphones, they face problems related to ICT infrastructure, such as unstable internet access and poor cellphone connections in the countryside and rural areas.

One of the challenges the cluster faces is how to increase local production and sales. Local demand is important, but around $87 \%$ of the flowers bought in the area come from Holambra (located $1200 \mathrm{~km}$ from the cluster), where production is dominated by Veiling®, a cooperative association of flower growers. Veiling ${ }^{\circledR}$ acts as a middleman that sells the flowers produced by its members using the same flower auction system adopted in the Netherlands. Members are pre-selected and pay a monthly fee to participate. Veiling also developed an electronic marketplace (Veiling On Line ${ }^{\circledR}$ http://www.veiling.com.br) that allows members to integrate supply and demand into the supply chain. This marketplace is classified by Hackney, Burn and Salazar (2004) as single vendor controlled, which is different from the VBC platform we developed.

The flower cluster studied has a lack of integration in the supply chain. Many economic agents perform multiple functions (production, wholesale and retail). Opportunistic behavior prevails. Additional problems include the lack of standardization of products, poor product mix and inconsistent and insufficient inventories of products due to local weather conditions (cold winters or very hot summers). Price inconsistencies (leading to cannibalization) and poorly managed business finances are also present. Since this is a buyers' market, retailers demand extended payment deadlines and default rates are high. Informal transactions (to evade taxes) are frequent, because there is no inventory or transparency in the flow of products. As reported by many members, the cluster must become more competitive. However, there are just a few associations that can support the implementation of common business goals and rules.

Another important factor is the lack of information about the production chain and market, particularly demand forecasts (quantity and consumer locations). Flower growers have no access to information about the needs of customers, which leads to losses of sales or excessive production. In the words of one flower grower: "retailers are not willing to commit to minimum purchases of our production and thus they fail to strengthen the supply chain", and "[if you] organize demand, production 
will respond to meet it". Similar cases are abound in the literature on ICT in agriculture, for example Ali and Kumar (2011) and Magesa, Michael and Ko (2015), who emphasized the need to empower farmers with market information and knowledge to improve networks and reach formal markets.

Wholesalers have the best information about supply and demand. Thus, information asymmetry between them and the flower growers is a concrete fact. Wholesalers establish negotiations based on the consignment of goods from the producers and at the same time rely on Holambra to procure products that are not available locally. They do not provide information about demand to local producers, even though locally grown flowers could be delivered faster. Estimates suggest that $50 \%$ of the production of cut flowers and potted plants does not reach the consumer market due to a lack of integration and poor information flow along the supply chain. The sharing of resources or processes is unusual in the cluster and information sharing only occurs informally. The lack of transparency, integration, information flow and governance hinders the development of the cluster.

Despite all these characteristics of the cluster, there was already a community that frequently met face to face to discuss the cluster's issues in their flower association; therefore, creating a VBC platform to improve interaction and business collaboration among them, with free participation and low costs, sounded like a good idea at first. Table 2 summarizes the main characteristics of the cluster studied.

Table 2

\section{The Context of the Studied Cluster}

\begin{tabular}{l}
\hline The context of the agricultural cluster* \\
\hline Scarce or out-of-date data about the cluster and the local flower market \\
\hline Lack of collaboration among cluster members \\
\hline Few associations integrating cluster members \\
\hline Opportunistic behaviour \\
\hline Lack of integration in the supply chain \\
\hline Asymmetry of information among economic agents (e.g., producers and wholesalers) \\
\hline Cluster poorly structured - lack of governance, business and product standards, market rules \\
\hline Many small and poorly organized firms in the cluster \\
\hline Little ICT usage by management of cluster firms \\
\hline Poor product mix \\
\hline Lack of financial control of businesses/reliance on informal transactions \\
\hline Lack of information about market needs and demands \\
\hline Lack of ICT infrastructure (internet and mobile connection) \\
\hline Not Source:
\end{tabular}

Note. Source: Research data.

(*) This symbol represents this context in Figures 3 and 4.

\section{Suggestions: an economic view of the problem (about September 2012)}

All the data collected in the problem awareness phase was presented during a meeting at the local State Agricultural Federation. These data allowed the participants and researchers to perform an assessment and discussion of the cluster profile and its competitiveness factors. This activity was key to design the first suggestion of the artifact (the VBC platform).

In the meeting, eight participants reported that the analysis presented was accurate and provided useful contributions considering the existing lack of consensus about the main problems of the flower 
sector. Two leaders of the cluster reinforced the need to organize the local flower market and streamline the exchange of information among cluster members.

The qualitative research instrument for assessing cluster competitiveness factors (Hoppen et al., 2016) was also used to design an initial draft of 21 information services that the VBC platform should provide, in order to enhance cluster competitiveness. These services were grouped into four categories:

1. Information sharing about external entities: market, suppliers, regulatory and legal information;

2. Information to support resource sharing: HR, production, financial, logistics and information systems resources;

3. Information to support collaborative HR training processes: technology, finance, market analysis, R\&D; and

\section{Commerce: selling, buying.}

These services could be used to enable collaboration and new forms of business transactions (such as conjoint sales or procurement). However, implementing all of them would result in a highly complex software platform that would require considerable resources and time before a working prototype could be available for testing. To reduce this complexity, we adopted an interactive design process (Sein, Henfridsson, Purao, Rossi, \& Lindgren, 2011). We discussed these 21 information services with cluster members to shortlist the most important. Two services were then selected: product demand and supply. These two services should reduce the time required to identify potential buyers or suppliers, two important factors since many products are perishable. One member commented: "If I' $m$ aware of where the demand is, I have the opportunity to meet this demand, even if I need to buy products from my competitors to fulfill urgent orders".

Participants also decided that information about product prices should not be made available on the platform in order to eliminate unfair competition and to prevent reverse auctions that could benefit some producers or wholesalers. Consequently, transactions would not be possible on the platform. Buyers and sellers had to contact each other to close deals using traditional channels (phone or e-mail). Therefore, some participants saw the VBC platform as a site for business contacts rather than an electronic marketplace like the one provided by Veiling ${ }^{\circledR}$.

At this point, it is worth highlighting the services not chosen by the participants. As already reported, out of the 21 information services that could enhance cluster competitiveness, participants only selected those associated to selling and buying. None of the other services related to information, processes or resource sharing were considered a priority. Even the creation of a forum to support communication and information sharing among members was rated as unimportant by the participants.

Participants decided that the prototype should initially include only cut flowers and ornamental plants because of their higher added value. They defined the members that would be able to add products to the database and organize revisions of the transactions performed using the platform. These participants also decided to join forces to invite a minimum of 40 cluster members to test the VBC platform. In this first testing phase, participants decided to include only flower growers and wholesalers as users and to only invite retailers after completing this phase.

Fifteen members of the cluster that participated in Flowers Associated volunteered to help to design and test the VBC platform. Most of them came from midsize firms and had a good level of education, with undergraduate courses in fields such as business management and agronomy. Since the start of the development process, we also tried to engage small producers, but interest was minimal.

At this point, it was clear that the VBC platform, if tested and proven successful, would require governance to become an institutionalized tool (a business platform or an electronic marketplace) for the cluster. However, none of the participants, leaders or associations showed any interest in taking over 
the coordination of the VBC platform, even after we had clarified our role as researchers and our intention to deliver the prototype to the community at no cost.

Since the cluster was poorly structured, members claimed that they did not have a formal institution that could lead the process of defining product standards and business rules to ensure governance on the VBC platform. Directors of Flowers Associated explained that they were not yet prepared to play this role. As a consequence, our research team coordinated all the efforts in the development and implementation of the VBC platform and supervised its use when testing the prototype. All participants supported this decision.

Despite limited collaboration among cluster members, the first version of the prototype encouraged the development of a shared database for cut flowers and ornamental plants, built with the help of some members of Flowers Associated. This development also generated the definition of business rules for the deals initiated on the VBC platform. For instance, when buyers did not complete the payment of the products they ordered, they were not allowed to place a new order. Participants also asked for a function to rate the reputation of VBC platform members.

Figure 3 represents the process of designing the VBC platform, in which tuning is related to defining the focus of the VBC platform to meet the goals prioritized by the flower growers. It illustrates key resistances in the design of the VBC platform, especially the difficulty in engaging small producers in this process. The participants also resisted suggestions to explore the possibilities of using the VBC platform for information and knowledge sharing or any sort of collaborative process. Their choices were individualistic: they wanted to use the VBC platform as a commercial platform for sales and procurement only. This can be explained by the context, illustrated in Table 1.

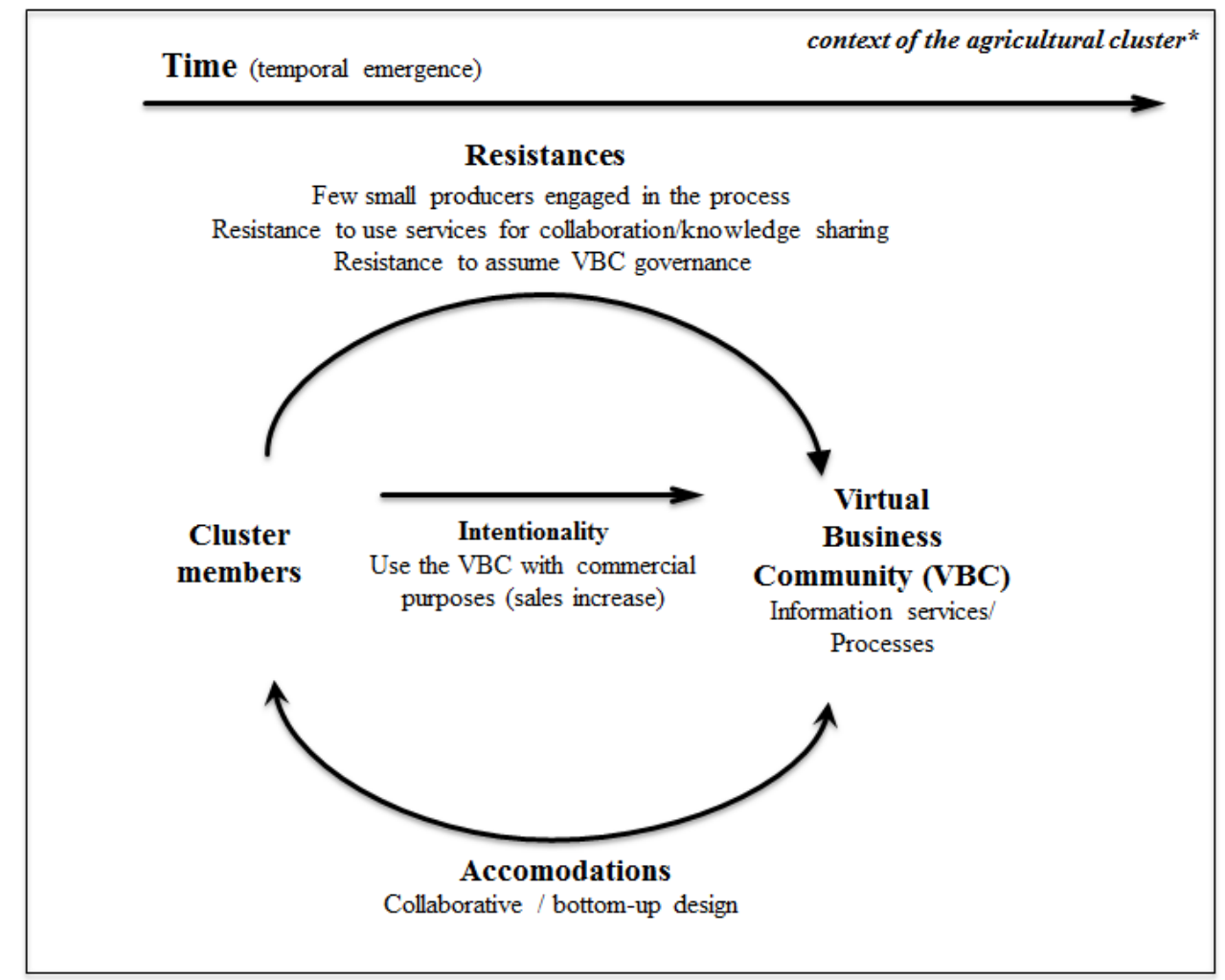

Figure 3. Mangle Movement \#1: Designing the VBC Platform

Accommodation was achieved through a bottom-up, participatory approach, which prioritized the functionalities cluster members wished to see included on the software platform. At this point, the level of complexity in the mangling process increased. 


\section{Development: creating and testing the VBC platform prototype (November 2012)}

Two months after the initial design meeting, a lunch meeting was organized so that a group of four cluster members (from Flowers Associated) could test the first version of the platform. The prototype was developed using C\#, JavaScript and trigger.io and was available for Windows, Android and IOS platforms on PCs, tablets, smartphones and other devices.

These members analyzed the services offered by the VBC platform, system layout and userfriendliness. Development then continued to incorporate a number of improvements suggested. These included developing information filters, a tool to assess members' reputations, a link to a help desk, consolidating a procedure to record and validate new products, and fixing bugs. Participants also asked for new members of the cluster to be included in the test group (mostly wholesalers and retailers). They also wanted to include landscape gardening plants and expand the product database to include scientific names.

Two additional development meetings were held in December 2012 and February 2013, with eight and nine cluster members, respectively. An updated version of the VBC platform prototype was presented. Participants approved its features and suggested some incremental improvements.

At the beginning of March 2013, an additional meeting with 17 participants was held at the university with the presence of researchers and small and midsize flower growers. Some participants reported that the prototype did not fully address the needs in their everyday business routines. They suggested new improvements to enhance the system by including product images, an e-mail service to inform users about new offers and orders, and the use of color coding to better distinguish offers from demand.

Participants set March 2013 as the date for when the prototype should be put to actual use. However, resources available to develop the features and infrastructure required in field testing (hosting, help desk) were insufficient. Additional time was needed to raise new research funds to improve and implement the prototype.

\section{The results: life is not a bed of roses (from March 2013 until January 2015)}

We spent most of 2013 trying to raise funds to continue the development of the VBC platform. We succeeded, but a new version of the prototype was only available for testing in September 2013. At that point, members of the cluster involved in the project showed resistance to using the prototype. They claimed to be too busy to devote time to the project, explaining that September (springtime in Brazil) was the best time for flower growers to do business.

A key requirement affecting the adoption of the VBC platform is the networking effect, that is, a group of participants must access the system and post the initial orders and offers that can attract additional members. Our goal was to start with a small group (around 30 people) and incrementally expand it. Nevertheless, participants reported a lack of real-life conditions when asked to add real offers and orders using the platform. They argued that there was not enough diversity considering the limited number of economic agents and products included. New buyers (retailers, wholesalers) had to be invited to join the community and use the system. But all flower growers involved declined to indicate potential clients. They feared they would be giving away valuable information if they shared their client base with other producers. One midsize flower grower explained: "I will only share my portfolio of client contacts [in the system] after everybody has done the same".

We worked on that problem and developed, after an extensive search on the internet, a database of 250 potential buyers of flowers, such as retailers, wedding planners, contractors and public garden caretakers, who could be invited to use the VBC platform. However, a group of participants feared the inclusion of these agents on the platform because some of them were already their clients. Although we structured the database using public data, participants were concerned about losing customers to other members of the cluster. At that point, midsize producers also expressed some doubts concerning changes 
to their business processes, while the few small producers involved felt uneasy about using the platform, arguing that they frequently experienced problems with their communication infrastructure (mobile services). Moreover, no effective leadership emerged in the community to drive the diffusion process.

These reactions contrasted with the optimistic mood observed during the development meeting in March 2013. In October 2013, in order to promote the VBC platform and to recruit new participants, the local branch of MAPA organized a seminar to discuss the flower grower sector. We were invited to present the VBC platform project, its main goals and potential benefits. MAPA lent its full support to the project and some of the participants actually expressed their interest in participating. However, no concrete moves or initiatives towards adopting the VBC platform were observed among these cluster members.

In April 2014, an important issue emerged in a new meeting between our research team and two cluster leaders, which shed some light on why ICT use was still low in the management of firms in the cluster. They pointed out that while a new generation was taking over the business and many employees used ICT and mobile technologies, many producers and retailers in the flower growing sector still favored paper-based controls and face-to-face or phone contacts.

These leaders also believed that inviting some agents from outside the cluster would be easier than engaging local members in testing the prototype, at least in the early stages. With the help of these two leaders, we endeavored to engage a small group of approximately 20 flower growers in the fieldtesting phase of the VBC platform. The group comprised midsize businesses whose owners and/or managers were familiar with ICT and included five garden plants suppliers from a neighboring state. This group invited other members.

Starting in August 2014, 31 companies used the VBC platform in real conditions. In January 2015, we carried out a questionnaire by phone with these participants and collected a total of 13 answers. Results indicated that only two of the 13 companies had done business through the VBC platform (four purchases altogether) and only one company indicated having sold something. When asked why they had not closed any deals, they reported that there was no demand for the products they offered or that they had not had time to use the VBC platform. One of the respondents stated that the system was suitable but he did not have the time to use it (or train his staff to do so). Most respondents reported that the platform was user-friendly and very useful. Some of them mentioned that they used it for price inquiries and to check what products members were offering, but they did not used it as a new sales channel. Figure 4 illustrates the mangling movement in the actual use of the VBC platform. 


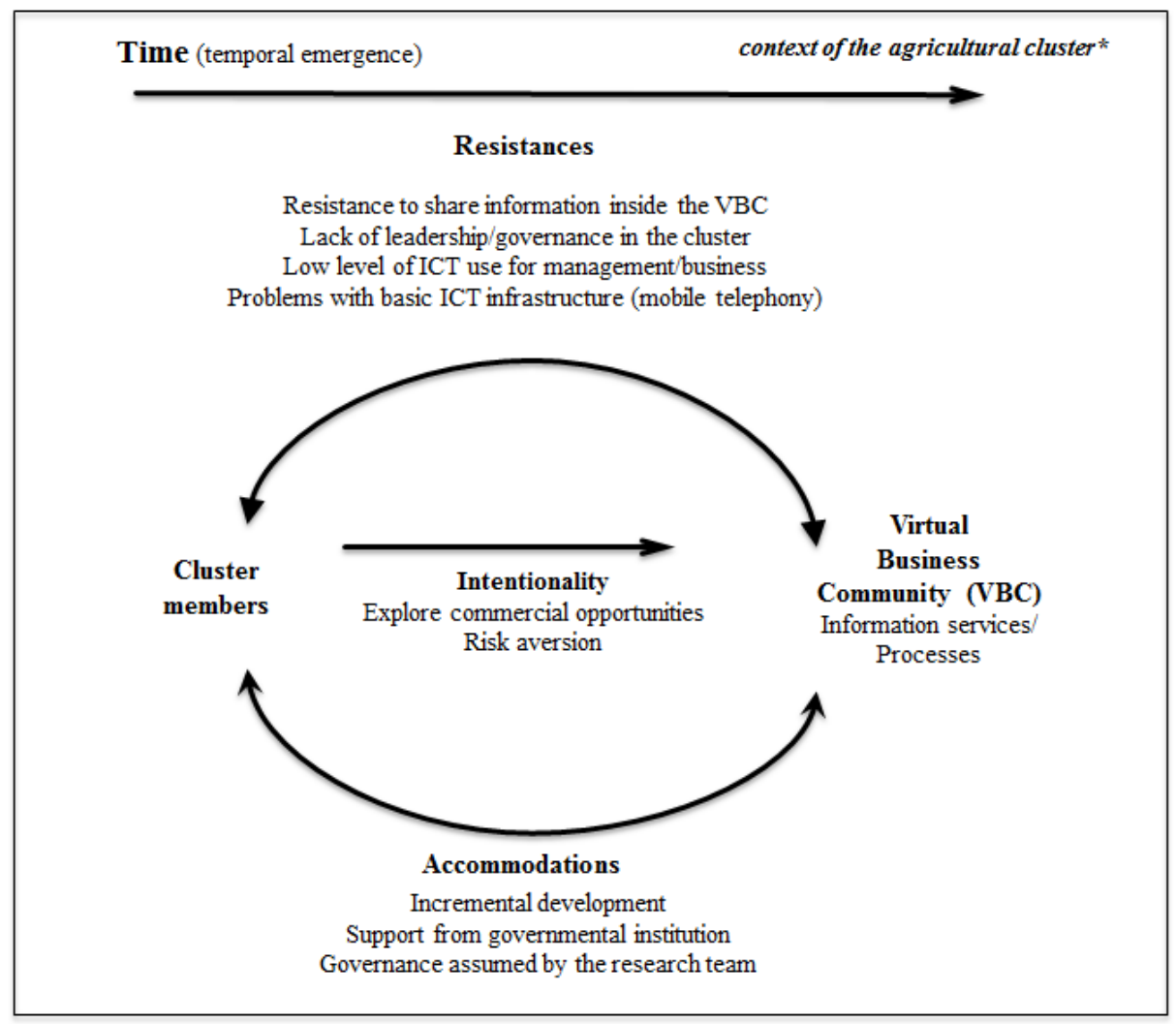

Figure 4. Mangle Movement \#2: VBC Platform in Use

Cluster members had intended to explore possible business opportunities through the VBC platform (selling, buying and checking prices and the offer of products). But their behavior also expressed risk aversion (e.g., losing clients to other members of the cluster when sharing information). This was an example of the chicken or the egg causality dilemma: users waited for others to act and share information before they would be willing to share it. The context of the cluster was determinant both in the process of mangling and in building governance. In this context, among other elements, opportunistic behavior and mistrust prevailed, while no leadership emerged that could coordinate the community.

During the tuning process, the incremental development adopted was an attempt to incorporate the features requested by the participants to make the VBC platform feasible, user-friendly and useful (features which were assessed positively in the evaluation). The research team also worked on the diffusion of the VBC platform, having secured governmental support (i.e., from MAPA) in promoting the project in the sector.

Governance was shown to be very important in the development of the VBC platform. Consequently, in the absence of an emerging coordination force in the cluster, the research team took over the governance of the community. However, accommodating actions were insufficient to encourage the adoption of the VBC platform.

\section{Discussion and Conclusion}

Our research project started with the initial idea of subjecting an application for ubiquitous commerce to a field test. This idea was then changed to developing a VBC platform for agriculture and several challenges arose in this process. To study these challenges, we discussed the tuning processes between participants and technology based on the sociomaterial perspective of the mangle of practice 
(Pickering, 1993, 1995; Stein et al., 2014), which helped us to analyze the series of resistances and accommodations in the design and application of the VBC platform (Figures 3 and 4).

Challenges also surfaced when carrying out a longitudinal design science research, as there is not yet an established methodology for this approach. Sein, Henfridsson, Purao, Rossi and Lindgren (2011) used action design research in an attempt to propose one such methodology, but their method required well-structured organizations when developing an artifact, which was not the case with the poorly structured cluster in this study. Therefore, we adopted a methodology tailored to the needs of our research (Figure 2). This methodology is based on a longitudinal, participatory approach that alternates system development actions with organizational development.

Some lessons can be learned from our experience considering the assumptions of the mangle of practice approach. The first one is the importance of understanding agricultural contexts in depth. Agriculture has unique features when compared with other industries in which the use of VBC platforms and electronic marketplaces is widespread. This is particularly true in developing countries, where unequal access to information gives information holders an advantage (FAO, 2013). In the agricultural sector, ICT is not commonly used to conduct businesses because of the poor educational level of users, a problem compounded by insufficient training and a lack of access to reliable basic ICT infrastructure (Moghaddam \& Khatoon-Abadi, 2013; Rao, 2007), particularly internet access. In such a scenario, it is precisely those who need the technology the most to gain access to markets - that is, small producers that are most affected by isolation.

The second lesson is that by adopting a collaborative, bottom-up, incremental development process for the VBC platform, it was possible to promote collaboration among cluster members to define basic business standards, rules and priority services. Participants understood the potential benefits of VBC platforms for their individual goals as something that provided access to improved market information, helped to identify demands and created a new sales channel for their products, which results in reduced information asymmetries. The technology agency was clear to the participants: they evaluated the VBC platform developed as very useful, user-friendly and appropriate to their economic goals.

However, human agency also required participants to understand the value offered to them when acting as members of a virtual community, which meant that they had to be willing to share information - for example, product inventories, diversity of offerings and demand for products, client lists, contacts, etc. In this regard, the culture and context of the agricultural cluster prevailed, since opportunistic behavior and the lack of trust and collaboration among its members were not overcome. These are key challenges to be faced in order to diffuse a VBC. While participants acknowledged the economic benefits of this platform, they preferred to avoid the risk of losing clients to other members in the community, which led to interorganizational inertia (Kim, Oh, \& Swaminathan, 2006). Since opportunist behavior prevailed and cluster members themselves could not establish strong leadership and governance to overcome these resistances, the project failed: the VBC platform was not diffused (Abbad, Senkel, \& Dari, 2012) and only a few businesses participated.

A third lesson is that the development of a VBC platform in poorly structured interorganizational arrangements, such as the agricultural cluster studied, should start with the development of governance structures and rules aimed at enhancing coordination and collaboration. In such contexts, the need for giving before getting has to be made explicit. Ideally, this process should count on legitimized leadership (Balkundi \& Kilduff, 2006; Wry, Lounsbury, \& Glynn, 2011) and start with the participation of members who have already experienced shared activities and collaboration (Ostrom, 1990). Legitimacy, as defined by Human and Provan (2000), may be considered as the generalized perception (by cluster members and customers) that the activities and the structure proposed (by the leadership) are desirable and appropriated. Furthermore, as cluster members often compete with each other, Human and Provan (2000) also stated that creating a separate administrative entity might be important when developing a VBC platform. 
All these elements are key requirements in the development of a structure based on interorganizational and personal relationships, and they constitute the main challenges when building a virtual network (Hackney et al., 2004).

As for theoretical contributions, our work shows a different view on the VBC concept, since the idea was to build a platform to support a virtual community not centered or led by a powerful actor, or "orchestrator" (Markus \& Loebbecke, 2013, p. 649). Instead, the idea was to set up a community ruled by peers (flower growers). By applying Pickering's mangle of practice approach to study this concept, we were able to analyze the challenges faced in its implementation in depth - the influence of agricultural contexts and the key elements involved (such as governance and leadership), which can prove useful for further studies on this subject. Another theoretical contribution of this article regards the use of the mangle of practice as an analytical lens applied in a longitudinal study to illustrate key aspects mentioned by Pickering. It can inspire future applications of this lens in applied research about technology use and organizations.

With regards to practical contributions, the lessons learned can be helpful for those who want to develop a collaborative VBC platform in similar settings, as well as for researchers interested in the use of ICT in agriculture, particularly in developing countries. Regarding public policies, we highlight the importance of generating knowledge about agricultural communities and clusters. This involves addressing not only demographic or economic data, but also mapping economic agents and chains, market structures and their needs in terms of ICT infrastructure and training, elements that must go hand in hand, particularly in the case of small producers. Investing in basic ICT infrastructure and developing management training while fostering a culture of collaboration are also important actions to help the development of VBC platforms in agricultural communities.

Some limitations are inherent to this study since its aim was to develop a VBC platform in agriculture. The poorly structured cluster chosen was shown to be a huge challenge to the development of a VBC. The long-term involvement of the researchers in this process could have also affected the interpretation of the results. These limitations should be addressed in future studies in similar contexts.

\section{Acknowledgements}

We thank the Brazilian research funding institutions CNPq (Conselho Nacional de Desenvolvimento Científico e Tecnológico) and FAPERGS (Fundação de Amparo à Pesquisa do Estado do Rio Grande do Sul) for their financial support.

\section{References}

Abbad, H., Senkel, M.-P., \& Dari, L. (2012). Understanding the non-adoption of EDI in the modern Moroccan food retailing industry. Supply Chain Forum: International Journal, 13(3), 82-91. https://doi.org/10.1080/16258312.2012.11517300

Ali, J., \& Kumar, S. (2011). Information and communication technologies (ICTs) and farmers' decisionmaking across the agricultural supply chain. International Journal of Information Management, 31(2), 149-159. https://doi.org/10.1016/j.ijinfomgt.2010.07.008

Bagozzi, R. P., \& Dholokin, U. M. (2002). Intentional social action in virtual communities. Journal of Interactive Marketing, 16(2), 2-21. https://doi.org/10.1002/dir.10006

Balkundi, P., \& Kilduff, M. (2006). The ties that lead: A social network approach to leadership. Leadership Quarterly, 17(4), 419-439. https://doi.org/10.1016/j.leaqua.2006.01.001 
Banker, R., Mitra, S., \& Sambamurthy, V. (2011). The effects of digital trading platforms on commodity prices in agricultural supply chains. Management Information Systems Quarterly, 35(3), 599-611.

Bauer, M. W. R., \& Gaskell, G. (2011). Pesquisa qualitativa com textos, imagens e som (9a ed.). Petrópolis: Vozes.

Berkowitz, W. R., \& Wolff, T. (2000). The spirit of the coalition building. Washington, DC: American Public Health Association.

Botsiou, M., \& Dagdilelis, V. (2013). Aspects of incorporation of ICT in the Greek agricultural enterprises: The case of a prefecture. Procedia Technology, 8, 387-396. https://doi.org/10.1016/j.protcy.2013.11.051

Chaudhuri, A. (2012). ICT for development: Solutions seeking problems? Journal of Information Technology, 27(4), 326-338. https://doi.org/10.1057/jit.2012.19

Das, B. (2014). ICTs adoption for accessing agricultural information: Evidence from Indian Agriculture. Agricultural Economics Research Review, 27(2), 199-208. https://doi.org/10.5958/09740279.2014.00024.x

Food and Agriculture Organization of the United Nations. (2013). ICT uses for inclusive agricultural value chain. Retrieved April 15, 2015, from http://www.fao.org/docrep/017/aq078e/aq078e.pdf

Franco L., Rosa, J., Barbosa, J., Costa, C., \& Yamin, A. (2011). MUCS: A model for ubiquitous commerce support. Electronic Commerce Research and Applications, 10(2), 237-246. https://doi.org/10.1016/j.elerap.2010.08.006

Giddens, A. (1984). The constitution of society. Cambridge, U. K.: Polity Press.

Gregor, S., \& Hevner, A. (2013). Positioning and presenting design science research. Management Information Systems Quarterly, 37(2), 337-355.

Hackney, R., Burn, J., \& Salazar, A. (2004). Strategies for value creation in electronic markets: Towards a framework for managing evolutionary change. Journal of Strategic Information Systems, 13(2), 91-103. https://doi.org/10.1016/j.jsis.2004.02.006

Hevner, A., March, S. T., Park, J., \& Ram, S. (2004). Design science research in information systems. Management Information Systems Quarterly, 28(1), 75-105.

Hoppen, N., Rigoni, E. H., Klein, A. Z., \& Ritter, Á. M. (2016). A qualitative research instrument to analyze organizational clusters' competitiveness factors. BASE - Revista de Administração e Contabilidade da Unisinos, 13(1), 2-18. http://dx.doi.org/10.4013/base.2016.131.01

Human, S. E., \& Provan, K. G. (2000). Legitimacy building in the evolution of small-firm multilateral networks: A comparative study of success and demise. Administrative Science Quarterly, 45(2), 327-365. https://doi.org/10.2307/2667074

Instituto Brasileiro de Floricultura. (2015). Mercado interno 12.2014. Retrieved April 15, 2015, from http://ibraflor.com/ns_mer_interno.php

Jones, M. (1999, December). Information systems and the double mangle: Steering a course between the Scylla of embedded structure and the Charybdis of strong symmetry. Proceedings of the IFIP WG8.2 \& WG8.6 Joint Working Conference on Information Systems: Current Issues and Future Changes (pp. 287-302). Helsinki, Finland.

Jones, M. (2014) A matter of life and death: Exploring conceptualizations and sociomateriality in the context of critical care. MIS Quarterly, 38(3), 895-925. 
Kambil, A., \& Van Heck, E. (1998). Reengineering the Dutch flower auctions: A framework for analyzing exchange organizations. Information Systems Research, 9(1), 1-19. https://doi.org/10.1287/isre.9.1.1

Kim, T., Oh, H., \& Swaminathan, A. (2006). Framing inter-organizational network change: A network inertia perspective. Academy of Management Review, 31(3), 704-720. https://doi.org/10.5465/amr.2006.21318926

Klein, A. Z., Freitas, J. C. da S., \& Barbosa, J. L. V. (2015). M-learning in practice: Using SMS for teaching and learning in undergraduate courses. Revista IEEE América Latina, 13(1), 321-329. https://doi.org/10.1109/tla.2015.7040665

Koh, J., Kim, Y.-G., Butler, B., \& Bock, G.-W. (2007). Encouraging participation in virtual communities. Communications of the ACM, 50(2), 69-73. https://doi.org/10.1145/1216016.1216023

Kuk, G., \& Davies, T. (2011). The roles of agency and artifacts in assembling open data complementarities. Proceedings of International Conference on Information Systems (ICIS), Shanghai, China, 32.

Lacerda, D. P., Dresch, A., Proença, A., \& Antunes, J. A. V., Jr. (2013). Design science research: Método de pesquisa para engenharia de produção. Gestão da Produção, 20(4), 741-761. http://dx.doi.org/10.1590/S0104-530X2013005000014

Läpple, D., Renwick, A., \& Thorne, F. (2015). Measuring and understanding the drivers of agricultural innovation: Evidence from Ireland. Food Policy, 51, 1-8. https://doi.org/10.1016/j.foodpol.2014.11.003

Leonardi, P. (2011). When flexible routines meet flexible technologies: Affordance, constraint, and the imbrication of human and material agencies. Management Information Systems Quarterly, 35(1), 147-167. Retrieved from http://www.jstor.org/stable/23043493

Magesa, M. M., Michael, K., \& Ko, J. (2015). Towards a framework for accessing agricultural market information. The Electronic Journal of Information Systems in Developing Countries, 66(3), 116. Retrieved from http://www.is.cityu.edu.hk/staff/isrobert/ejisdc/66-3.pdf

Markus, M. L., \& Loebbecke, C. (2013). Commoditized digital processes and business community platforms: New opportunities and challenges for digital business strategies. Management Information Systems Quarterly, 37(2), 649-653.

Martini, A., Massa, S., \& Testa, S. (2013). The firm, the platform and the customer: A "double mangle" interpretation of social media innovation. Information and Organization, 23(3), 198-213. https://doi.org/10.1016/j.infoandorg.2013.07.001

Miles, M. B., \& Huberman, A. M. (1994). Qualitative data analysis: An expanded sourcebook (2nd ed.). Newbury Park: Sage Publications.

Moghaddam, B. K., \& Khatoon-Abadi, A. (2013). Factors affecting ICT adoption among rural users: A case study of ICT center in Iran. Telecommunications Policy, 37(11), 1083-1094. https://doi.org/10.1016/j.telpol.2013.02.005

Ostrom, E. (1990) Governing the commons: The evolution of institutions for collective action. Cambridge: Cambridge University Press.

Peffers, K., Tuunanen, T., Rothenberger, M. A., \& Chatterjee, S. (2007). A design science research methodology for information systems research. Journal of Management Information Systems, 24(3), 45-77. https://doi.org/10.2753/mis0742-1222240302 
Pickering, A. (1993). The mangle of practice: Agency and emergence in the sociology of science. The American Journal of Sociology, 99(3), 559-589. https://doi.org/10.1086/230316

Pickering, A. (1995). The mangle of practice: Time, agency and science. Chicago: University of Chicago Press.

Porter, C. E. (2004). A typology of virtual communities: A multi-disciplinary foundation for future research. Journal of Computer-Mediated Communication, 10(1). http://dx.doi.org/10.1111/j.1083-6101.2004.tb00228.x

Rao, N. H. (2007). A framework for implementing information and communication technologies in agricultural development in India. Technological Forecasting and Social Change, 74(4), 491518. https://doi.org/10.1016/j.techfore.2006.02.002

Rothaermel, F. T., \& Sugiyama, S. (2001). Virtual internet communities and commercial success: Individual and community level theory grounded in the typical case of Time-Zone.com. Journal of Management, 27(3), 297-312. https://doi.org/10.1016/s0149-2063(01)00093-9

Sein, O., Henfridsson, O., Purao, S., Rossi, M., \& Lindgren, R. (2011). Action design research. Management Information Systems Quarterly, 35(1), 37-56. Retrieved from http://www.jstor.org/stable/23043488

Steinkuehler, C. (2006). The mangle of play. Games and Culture, 1(3), 199-213. http://dx.doi.org/10.1177/1555412006290440

Stein, M. K., Newell, S., Wagner, E. L., \& Galliers, R. D. (2014). Felt quality of sociomaterial relations: Introducing emotions into sociomaterial theorizing. Information and Organization, 24(3), 156175. https://doi.org/10.1016/j.infoandorg.2014.05.003

Svahn, F., Henfridsson, O., \& Yoo, Y. (2009, December). A threesome dance of agency: Mangling the sociomateriality of technological regimes in digital innovation. Proceedings of International Conference on Information Systems (ICIS), Phoenix, Arizona, USA, 30.

The World Bank. (2011). ICT in Agriculture: connecting smallholders to knowledge, networks and institutions (Report $\mathrm{n}^{\mathrm{o}}$ 64605). Retrieved April 15, 2015, from http://documents. worldbank.org/curated/en/455701468340165132/pdf/646050ESW0P1180lture 0e0Sourcebook12.pdf

Vaishnavi, V., \& Kuechler, W. (Eds.). (2004). Design science research in information systems. Retrieved June 14, 2013, from http://desrist.org/design-research-in-information-systems

Vallauri, U. (2014). Transition Belsize Veg Bag scheme: The role of ICTs in enabling new voices and community alliances around local food production and consumption. Futures, 62, 173-180. https://doi.org/10.1016/j.futures.2014.04.008

Venters, W., Oborn, E., \& Barret, M. (2014). A trichordal temporal approach to digital coordination: The sociomaterial mangling of the CERN grid. Management Information Systems Quarterly, 38(3), 927-949.

Wry, T., Lounsbury, M., \& Glynn, M. A. (2011). Legitimating nascent collective identities: Coordinating cultural entrepreneurship. Organization Science, 22(2), 449-463. https://doi.org/10.1287/orsc.1100.0613 


\section{Authors' Profiles}

Norberto Hoppen

Avenida Unisinos, 950, 93022-000, São Leopoldo, RS, Brazil. E-mail address: norbertohoppen@ gmail.com

Amarolinda da Costa Zanela Klein

Avenida Unisinos, 950, 93022-000, São Leopoldo, RS, Brazil. E-mail address: amaroklein@ gmail.com

Eduardo Henrique Rigoni

Avenida Unisinos, 950, 93022-000, São Leopoldo, RS, Brazil. E-mail address: ehrigoni@ gmail.com 